\title{
Expert Advisor (EA) Evaluation System Using Web-based ELECTRE Method in Foreign Exchange (Forex) Market
}

\author{
Satibi Satibi ${ }^{13, *}$, Catur Edi Widodo ${ }^{2}$, and Farikhin Farikhin ${ }^{2}$ \\ ${ }^{1}$ Master of Information Systems, School of Postgraduate Studies, Diponegoro University, Semarang - Indonesia \\ ${ }^{2}$ Physics Department of Science and Mathematics Faculty, Diponegoro University, Semarang - Indonesia \\ ${ }^{3}$ Department of Informatics Management, AMIK Selatpanjang, Meranti Is land - Indonesia
}

\begin{abstract}
This research aims to optimize forex trading profit automatically using EA but its still keep considering accuracy and drawdown levels. The evaluation system will classify EA performance based on trading market sessions (Sydney, Tokyo, London and New York) to determine the right EA to be used in certain market sessions. This evaluation system is a web-based ELECTRE methods that interact in real-time with EA through web service and are able to present real-time charts performance dashboard using web socket protocol communications. Web applications are programmed using NodeJs. In the testing period, all EAs had been simulated 24 hours in all market sessions for three months, the best EA is valued by its profit, accuracy and drawdown criteria that calculated using web-based ELECTRE method. The ideas of this research are to compare the best EA on testing period with collaboration performances of each best classified EA by market sessions. This research uses three months historical data of EUR/USD as testing period and other 3 months as validation period. As a result, performance of collaboration four best EA classified by market sessions can increase profits percentage consistently in testing and validation periods and keep securing accuracy and drawdown levels.
\end{abstract}

\section{Introduction}

In determining the investment strategy in the foreign exchange market, decision makers have important roles and responsibilities to determine risks and profit targets. Decision makers are also required to be able to make three important decisions, namely: 1 . Prices will move up or down; 2. Determine buying or selling decisions; 3 . How long to hold the position that has been opened [1]. Due to the importance of decision-making role in forex trading market, it is necessary to have a system to record and evaluate the history of transactions that have been done before in real-time so that it can help to provide performance reports from previous transactions.

Nowadays it is the era of computer and information technology that has been developing quite rapidly. For sure, this evolution affecting the way of trading transactions method in the forex market to continues to grow. Utilizing current technology allows Traders to perform real-time analysis and trading over the internet. Forex trading can also be done automatically based on EA (Expert Advisor) without human intervention, with automatically analytics and transactions using EA in forex transaction negotiation is to avoid human intervention that is usually influenced by emotions, anxiety, stress and other things. Therefore, trading by using EA becomes a solution to eliminate the elements of human intervention that are volatile. Even studies in
2010 concluded $45 \%$ of negotiation system in the forex market was conducted using EA [2].

Although the percentage of the use of EA in forex trading is very large, but analysis process and transaction history evaluation usually had been done only limited to transaction history analysis that found in Metatrader software, which its not optimal when used as EA performance evaluation data. With the integration of EA supported by calculations based on real-time web-based ELECTRE method will be more optimal in providing the best choice of several EA alternatives based on trading market sessions.

In addition to being able to perform analysis and transaction in the forex market automatically, the EA also has the ability to interact with the web service, so it can be integrated with algorithms that are applied to web based applications that provide supporting information for the EA itself. Forex trading research on the forex market has been done a lot before, including forex forecasting using ANN methods [3], multi-agency financial decision support system with Fuzzy logic [4] and Web-based decision support systems with ANN for forecasting and forex trading [5]. However, this research focuses on evaluating the performance of ten open source EA that available on the official MQL4 (MetaQuotes Language 4) community website, although this evaluation system can still be used on all types of EAs either paid or created by traders who master the

\footnotetext{
Corresponding author: satibi@,batam.mobi
} 
MQL4 programming language, by inserting a line of MQL4 code created in this evaluation system in order to interact with the web service and utilizing historical data of previous relevant currency movements to simulate the EAs.

\section{Method}

\subsection{Data acquisition}

Historical currency movement data that used to simulate trading charts movement in MetaTrader software is downloaded from Histdata.com, while the EAs trading transaction data acquired in real-time on the web-based ELECTRE application through web service which is also integrated with web socket for Displaying EA performance graphs in real-time on the dashboard. These acquired transaction data saved in database, this database will be classified based on trading market sessions to get the best performing EA in each trading market session. Classifications process of market session is recognized by trading open position that done by real-time EA transaction. The flow of data acquisition process as shown in Figure 1.

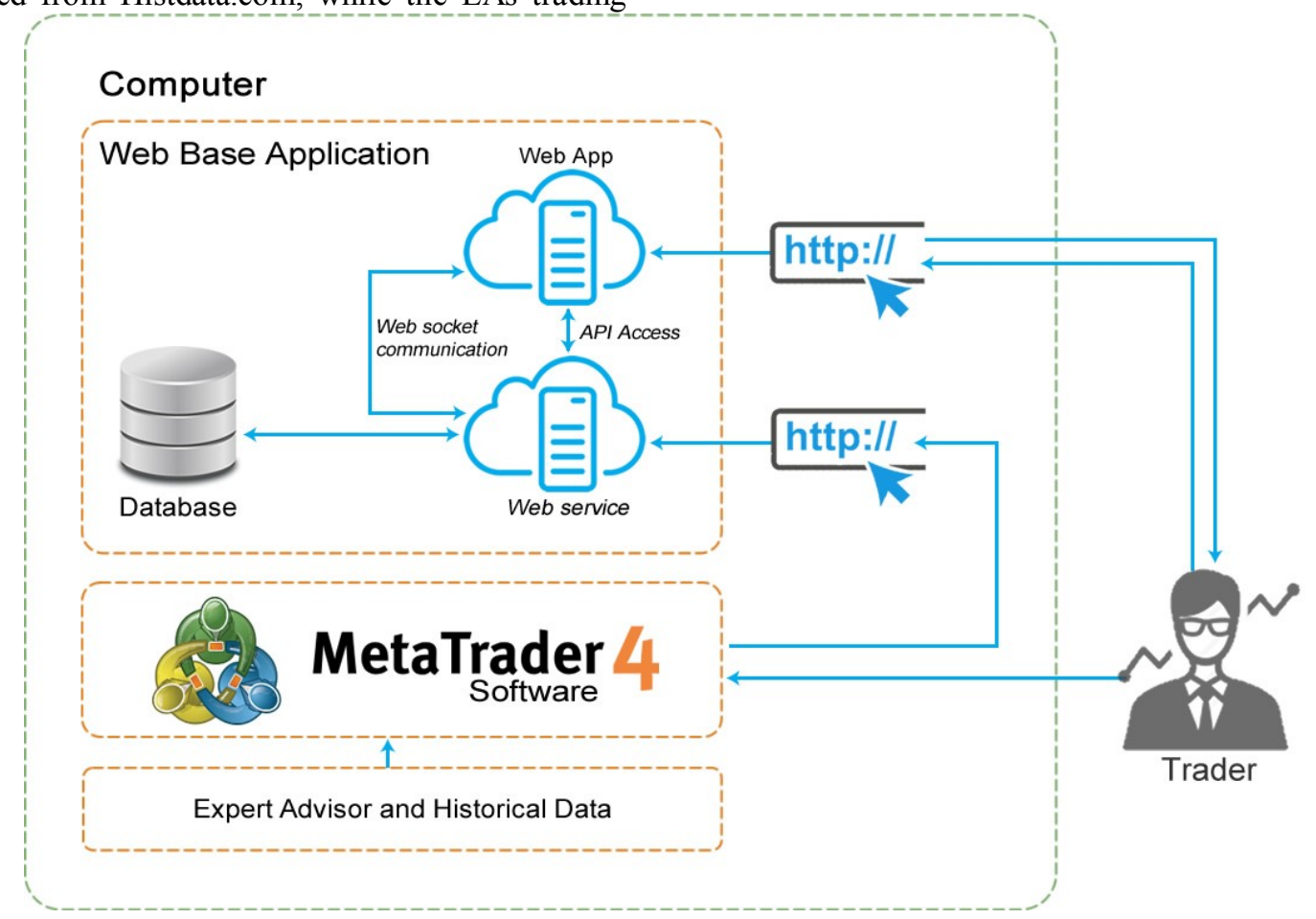

Fig. 1. Data acquisition process of EA transactions

\subsection{ELECTRE method}

The ELECTRE method is one of the multi criteria decision analysis methods which is an acronym of Elimination Et Choix Traduisant la Realité or in English means Elimination and Choice Expressing Reality, first introduced in 1965 by the SEMA consulting firm in Europe [6]. The modeling with the ELECTRE method includes six stages, ie :

1. Normalization of matrix

Normalization process will produce $\mathrm{R}$ matrix, that calculated by :

$$
\mathrm{r}_{\mathrm{ij}}=\frac{x_{i j}}{\sqrt{\sum_{i=1}^{m} x_{i j}^{2}}}
$$

2. To weight the normalized matrix, multiply that $\mathrm{R}$ matrix values by the weight of each criterion using following equation:

$$
v_{i j}=w_{i} r_{i j} .
$$

3. Determining concordance and discordance index sets.

Concordance index calculated by:

$$
C_{k l}=\left\{j \mid v_{k j} \geq v_{i j}\right\} ; \text { untuk } j=1,2, \ldots, n
$$

Meanwhile, following equation is to calculate discordance index :

$$
D_{k l}=\left\{j \mid v_{k j}<v_{i j}\right\} ; \text { untuk } j=1,2, \ldots, n
$$

4. Concordance and discordance matrix Concordance matrix obtained by :

$$
c_{k l}=\sum_{j \in C_{k l}} W_{j}
$$

Below equation is used to obtain discordance matrix:

$$
d_{k l}=\frac{\max \left\{\left|v_{k j}-v_{l j}\right|\right\}_{j \in D_{k l}}}{\max \left\{\left|v_{k j}-v_{l j}\right|\right\}_{\forall j}}
$$


5. Dominance concordance and discordance matrix

To determine dominance concordance matrix :

$$
\underline{c}=\frac{\sum_{k=1}^{m} \sum_{l=1}^{m} c_{k l}}{m(m-1)}
$$

Elements of $\mathrm{F}$ matrix specified by:

$$
f_{k l}=\left\{\begin{array}{l}
1, j i k a c_{k l} \geq \underline{c} \\
0, j i k a c_{k l}<\underline{c}
\end{array}\right.
$$

To determine dominance discordance matrix :

$$
\underline{d}=\frac{\sum_{k=1}^{m} \sum_{l=1}^{m} d_{k l}}{m(m-1)}
$$

Elements of $\mathrm{G}$ matrix specified by :

$$
g_{k l}=\left\{\begin{array}{l}
1, j i k a d_{k l} \geq \underline{d} \\
0, j i k a d_{k l}<\underline{d}
\end{array}\right.
$$

6. Determining the aggregate dominance matrix

Aggregation of the dominance matrix indicates the sequence of partial preferences of the available alternatives, to obtain this aggregate dominance matrix, following equation is used :

$$
e_{k l}=f_{k l} \times g_{k l}
$$

From that calculation will produce the E matrix which gives sequence of options from each available alternative, if $e_{k l}=1$ then alternative $A_{k}$ is a better alternative than $A_{l}$. So, the rows in the E matrix that having less $e_{k l}=1$ can be eliminated, as well as other rows calculation can be eliminated until remaining first row as selected best EA alternative.

\section{Results and discussion}

Required data acquisition process in this research is EAs transaction data from ten simulated EA and percentage of profit, accuracy and drawdown from each EA performance.

a. Transactions data acquisition process

Data acquisition process in web-based ELECTRE application is done in real-time when trading simulation is executed on MetaTrader software, EA will send trading transaction data to web service such as alt_id, ticket_id, open_time, close_time, type, lots, symbol, open_price, close_price and profit fields.

b. Meanwhile, the value data that consisting of profit, accuracy and drawdown were obtained by calculating the percentage of that three criteria based on transaction history data, while capital $=5000, \%$ Profit $=(($ profit + loss $) /$ capital $) \times 100, \%$ Accuracy $=\left(\sum\right.$ profit positions $/ \sum$ all positions $) \times 100$, Drawdown $=$ (maximum floating / capital) x 100. This calculation

\begin{tabular}{|c|c|c|c|c|c|c|c|}
\hline $\begin{array}{l}\text { Alt } \\
\text { ID }\end{array}$ & $\begin{array}{l}\text { Cri } \\
\text { ID }\end{array}$ & Value & Step & $\begin{array}{l}\text { Alt } \\
\text { ID }\end{array}$ & $\begin{array}{l}\text { Cri } \\
\text { ID }\end{array}$ & Value & Step \\
\hline 1 & 1 & 1.89 & 1 & 1 & 1 & -10.67 & 2 \\
\hline 1 & 2 & 39.29 & 1 & 1 & 2 & 26.36 & 2 \\
\hline 1 & 3 & -0.52 & 1 & 1 & 3 & -11.78 & 2 \\
\hline 2 & 1 & -13.69 & 1 & 2 & 1 & 3.08 & 2 \\
\hline 2 & 2 & 61.11 & 1 & 2 & 2 & 80 & 2 \\
\hline 2 & 3 & -17.87 & 1 & 2 & 3 & -1.32 & 2 \\
\hline 3 & 1 & -49.56 & 1 & 3 & 1 & -20.76 & 2 \\
\hline 3 & 2 & 51.54 & 1 & 3 & 2 & 53.62 & 2 \\
\hline 3 & 3 & -13.77 & 1 & 3 & 3 & -23.35 & 2 \\
\hline 4 & 1 & 6.76 & 1 & 4 & 1 & 4.11 & 2 \\
\hline 4 & 2 & 100 & 1 & 4 & 2 & 100 & 2 \\
\hline 4 & 3 & -2.62 & 1 & 4 & 3 & -0.17 & 2 \\
\hline 5 & 1 & -45.19 & 1 & 5 & 1 & 40.22 & 2 \\
\hline 5 & 2 & 53.33 & 1 & 5 & 2 & 72.28 & 2 \\
\hline 5 & 3 & -90.29 & 1 & 5 & 3 & -40.94 & 2 \\
\hline 6 & 1 & 6.38 & 1 & 6 & 1 & 10.34 & 2 \\
\hline 6 & 2 & 40.35 & 1 & 6 & 2 & 40.82 & 2 \\
\hline 6 & 3 & -1.49 & 1 & 6 & 3 & -0.22 & 2 \\
\hline 7 & 1 & 29.43 & 1 & 7 & 1 & 7.41 & 2 \\
\hline 7 & 2 & 70.63 & 1 & 7 & 2 & 64.62 & 2 \\
\hline 7 & 3 & -2.64 & 1 & 7 & 3 & -52.85 & 2 \\
\hline 8 & 1 & 17.7 & 1 & 8 & 1 & 13 & 2 \\
\hline 8 & 2 & 100 & 1 & 8 & 2 & 100 & 2 \\
\hline 8 & 3 & -15.21 & 1 & 8 & 3 & -7.38 & 2 \\
\hline 9 & 1 & 31.55 & 1 & 9 & 1 & 43.25 & 2 \\
\hline 9 & 2 & 81.93 & 1 & 9 & 2 & 76.92 & 2 \\
\hline 9 & 3 & -42.12 & 1 & 9 & 3 & -7.37 & 2 \\
\hline 10 & 1 & -15.72 & 1 & 10 & 1 & 1.02 & 2 \\
\hline 10 & 2 & 47.2 & 1 & 10 & 2 & 49.74 & 2 \\
\hline 10 & 3 & -39.62 & 1 & 10 & 3 & -27.18 & 2 \\
\hline
\end{tabular}
will be obtained value as shown in Table 1 and Table 2.
Table 1. Value of each criteria without market classification

Table 2. Value of each criteria by market sessions

\begin{tabular}{|c|c|c|c|c|c|c|}
\hline $\begin{array}{c}\text { Alt } \\
\text { ID }\end{array}$ & $\begin{array}{c}\text { Cri } \\
\text { ID }\end{array}$ & Sydney & Tokyo & London & $\begin{array}{c}\text { New } \\
\text { york }\end{array}$ & Step \\
\hline 1 & 1 & 5.92 & 7.21 & -1.53 & -2.74 & 1 \\
\hline 1 & 2 & 46.67 & 50 & 36.36 & 38.1 & 1 \\
\hline 1 & 3 & -0.8 & -0.8 & -1.02 & -1.01 & 1 \\
\hline 2 & 1 & 5 & 2.96 & -17.65 & -10.7 & 1 \\
\hline 2 & 2 & 100 & 83.33 & 45.45 & 42.86 & 1 \\
\hline 2 & 3 & -1.5 & -3.04 & -6.94 & -4.6 & 1 \\
\hline 3 & 1 & -6.1 & -8.46 & -43.79 & -7.39 & 1 \\
\hline 3 & 2 & 52.63 & 52.78 & 49.33 & 53.53 & 1 \\
\hline 3 & 3 & -2.79 & -2.79 & -3.97 & -3.97 & 1 \\
\hline 4 & 1 & 2.2 & 3.2 & 3.56 & 2.23 & 1 \\
\hline 4 & 2 & 100 & 100 & 100 & 100 & 1 \\
\hline 4 & 3 & -1.43 & -1.43 & -4.63 & -0.76 & 1 \\
\hline 5 & 1 & 1.51 & -6.25 & -45.34 & -17.43 & 1 \\
\hline 5 & 2 & 71.43 & 50 & 53.85 & 54.55 & 1 \\
\hline 5 & 3 & -1.42 & -3.88 & -49.41 & -21.55 & 1 \\
\hline 6 & 1 & 6.63 & 6.35 & 0.37 & 1.96 & 1 \\
\hline 6 & 2 & 53.85 & 60 & 36.36 & 40 & 1 \\
\hline 6 & 3 & -0.83 & -0.7 & -0.84 & -0.84 & 1 \\
\hline 7 & 1 & 18.54 & 10.6 & 16.35 & 5.56 & 1 \\
\hline 7 & 2 & 69.64 & 72.09 & 71.64 & 70.18 & 1 \\
\hline 7 & 3 & -8.81 & -8.81 & -3.5 & -6.34 & 1 \\
\hline 8 & 1 & 11.86 & 4.11 & 3.23 & 3.81 & 1 \\
\hline 8 & 2 & 100 & 100 & 100 & 100 & 1 \\
\hline 8 & 3 & -18.35 & -21.61 & -23.84 & -2.98 & 1 \\
\hline 9 & 1 & 6.2 & 6.77 & 21.46 & 15.96 & 1 \\
\hline 9 & 2 & 81.25 & 80 & 84 & 83.72 & 1 \\
\hline & & & & & & \\
\hline
\end{tabular}




\begin{tabular}{|c|c|c|c|c|c|c|}
\hline $\begin{array}{c}\text { Alt } \\
\text { ID }\end{array}$ & $\begin{array}{c}\text { Cri } \\
\text { ID }\end{array}$ & Sydney & Tokyo & London & $\begin{array}{c}\text { New } \\
\text { york }\end{array}$ & Step \\
\hline 9 & 3 & -20.66 & -20.66 & -35.22 & -35.22 & 1 \\
\hline 10 & 1 & 1.56 & 5.16 & -14.16 & 0 & 1 \\
\hline 10 & 2 & 48.05 & 46.59 & 46.2 & 46.36 & 1 \\
\hline 10 & 3 & -7.18 & -8.82 & -10.76 & -10.76 & 1 \\
\hline 1 & 1 & -6.68 & -5.19 & 0.96 & -5.04 & 2 \\
\hline 1 & 2 & 17.31 & 22.81 & 36 & 28.95 & 2 \\
\hline 1 & 3 & -0.88 & -0.88 & -1.08 & -1.08 & 2 \\
\hline 2 & 1 & 4 & 2.46 & -1.13 & -2.38 & 2 \\
\hline 2 & 2 & 100 & 83.33 & 75 & 66.67 & 2 \\
\hline 2 & 3 & -2.46 & -3.04 & -4.59 & -4.59 & 2 \\
\hline 3 & 1 & -3.07 & -6.29 & -29.51 & -9.13 & 2 \\
\hline 3 & 2 & 38.1 & 44.62 & 53.85 & 59.24 & 2 \\
\hline 3 & 3 & -1.55 & -2.79 & -5.4 & -5.4 & 2 \\
\hline 4 & 1 & 0.08 & 1.08 & 2.49 & 2.53 & 2 \\
\hline 4 & 2 & 100 & 100 & 100 & 100 & 2 \\
\hline 4 & 3 & -0.04 & -0.12 & -1.19 & -4 & 2 \\
\hline 5 & 1 & 4.06 & 5.54 & 35.25 & 25.67 & 2 \\
\hline 5 & 2 & 68.42 & 64 & 75.68 & 70.69 & 2 \\
\hline 5 & 3 & -9.6 & -19.1 & -65.58 & -52.86 & 2 \\
\hline 6 & 1 & 2.81 & 2.12 & 3.11 & 4.18 & 2 \\
\hline 6 & 2 & 44.44 & 37.5 & 43.48 & 37.5 & 2 \\
\hline 6 & 3 & -0.68 & -0.74 & -0.84 & -0.84 & 2 \\
\hline 7 & 1 & -12.31 & -28.86 & 51.99 & 31.42 & 2 \\
\hline 7 & 2 & 63.64 & 61.11 & 68.75 & 70.59 & 2 \\
\hline 7 & 3 & -19.18 & -19.18 & -58.77 & -85.32 & 2 \\
\hline 8 & 1 & 4.3 & 4.19 & 1.78 & 5.69 & 2 \\
\hline 8 & 2 & 100 & 100 & 100 & 100 & 2 \\
\hline 8 & 3 & -10.4 & -8.66 & -6.26 & -8.14 & 2 \\
\hline 9 & 1 & 8.42 & 10.02 & 25.8 & 15.12 & 2 \\
\hline 9 & 2 & 76 & 69.23 & 77.42 & 77.19 & 2 \\
\hline 9 & 3 & -3.5 & -20.72 & -36.83 & -16.12 & 2 \\
\hline 10 & 1 & -1.92 & 1.68 & -8.22 & -7.8 & 2 \\
\hline 10 & 2 & 51.61 & 56.52 & 50.91 & 45.28 & 2 \\
\hline 10 & 3 & -7.45 & -7.18 & -4.78 & -4.78 & 2 \\
\hline & & & & & & \\
\hline
\end{tabular}

c. Determining the weight of each criteria, the criteria weight in this case obtained from online questionnaire results, the questionnaire gives criteria weight for profit $=3.83 \%$, accuracy $=2.39 \%$ and drawdown $3.27 \%$.

d. Normalize the matrix by specifying value for each matrix index of all alternatives per criterion, value of profit calculation example :

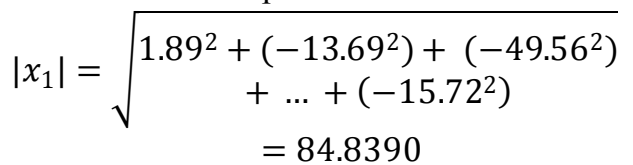

To get profit value from first and second EAs :

$$
\begin{aligned}
& r_{11}=\frac{x_{11}}{\left|x_{1}\right|}=\frac{1.89}{84.8390}=0.0223 \\
& r_{21}=\frac{x_{11}}{\left|x_{1}\right|}=\frac{-13.69}{84.8390}=-0.1614 \\
& r_{\ldots}=\cdots
\end{aligned}
$$

e. The same way is used to determine the value of normalization on accuracy and drawdown criterias value.

f. Normalized matrix weighting is obtained by multiplying normalized matrix values by the weight of each criterion, eg. :

$$
\begin{aligned}
& v_{11}=0.0223 \times 3.83=0.0853, \\
& v_{21}=-0.1614 \times 3.83=-0.6180, \ldots
\end{aligned}
$$

g. Determining concordance and discordance index sets by comparing an alternative with another alternative based on the same criterion, if selected value is greater then that index is used as a concordance index, and if the index value is smaller it will be used as a discordance index, eg. : $C_{12}=\{1,3\}, C_{13}=\{1,3\}$

h. Calculates concordance and discordance matrices. Concordance matrix is obtained by summing weights based on concordance index, eg. : $C_{12}=3.83+3.27$ $=7.1000$. While discordance matrix is obtained by getting value of difference between two criterion values based on discordance index then taken the highest value from it, this value will divided by the highest value of difference from all indexes comparison..

i. Dominance matrix of concordance and discordance is obtained by determining the threshold value first, then determining the dominance concordance matrix by comparing concordance and discordance matrix elements with the threshold value of each matrix, if the value of each element is greater than the threshold value will give a value of 1 And gives a value of 0 if it is smaller than the threshold value.

j. Aggregate dominance matrix is obtained by multiplying the dominance matrix element of concordance and dominance discordance matrix elements. The alternative with $e_{k l}=1$ will be eliminated while alternative with the most of $e_{k l}=1$ will be selected as the best alternative as shown in Figure 2.

k. These calculation steps are also used to get the best EAs in the best EA selection process based on market sessions as shown in Figure 3.

1. In order to get optimal results, if there are more than one EAs with same performances appeared in the same market session, only one EAs will be selected as best EA on that market session based on highest criteria weight priority.

\subsection{Results Evaluation and validation}

EAs performance evaluation and validation of ELECTRE method calculation had been tested using different test time data, October to December (2016) as testing period and January to march (2017) as validation period with different transaction data amounts, so that the results obtained as in Figure 4 and 5. 
10 EAs Performance Chart

Alternatives: 10, Criterias: 3

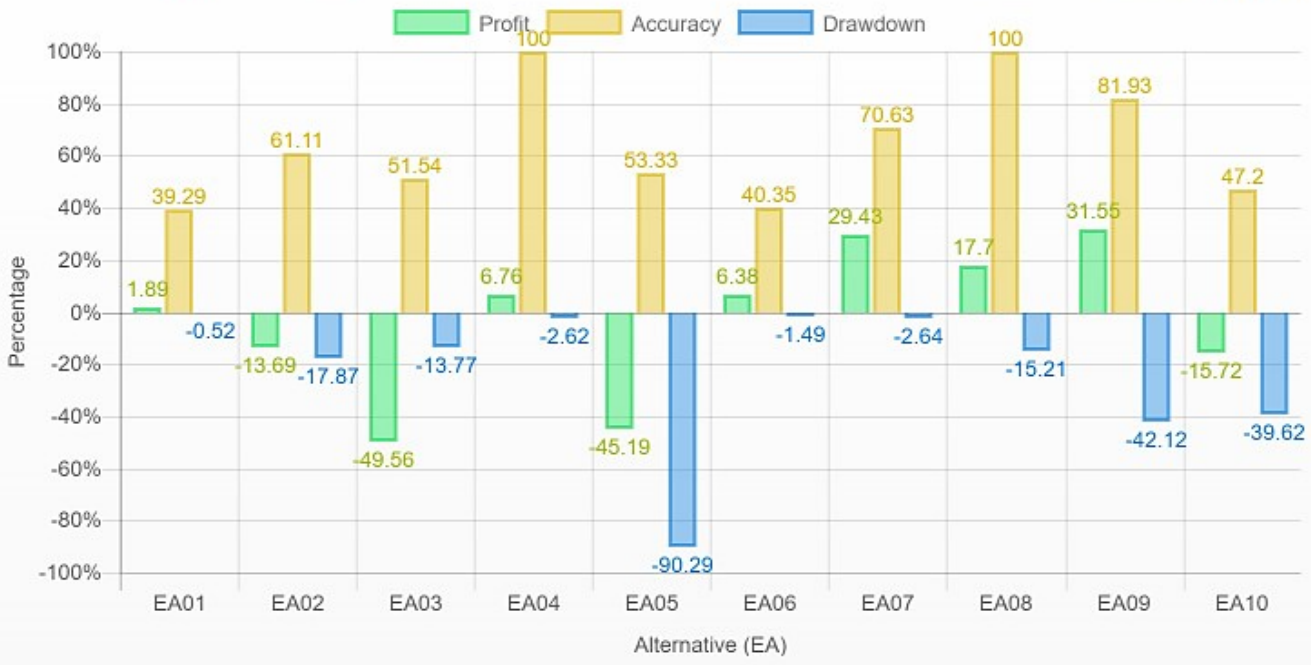

Fig. 2. Ten EAs performances in testing period

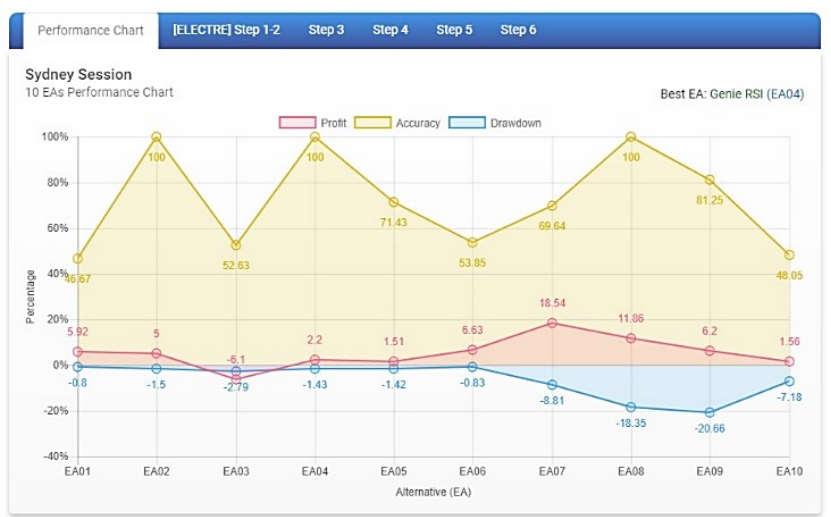

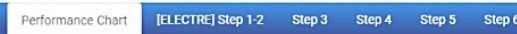

Tokyo Session
10 EAS Performance chart

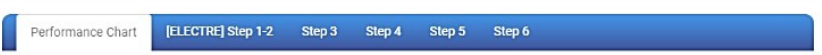

London Session
10 EAs Performance

st EA: Reco System (EA07)
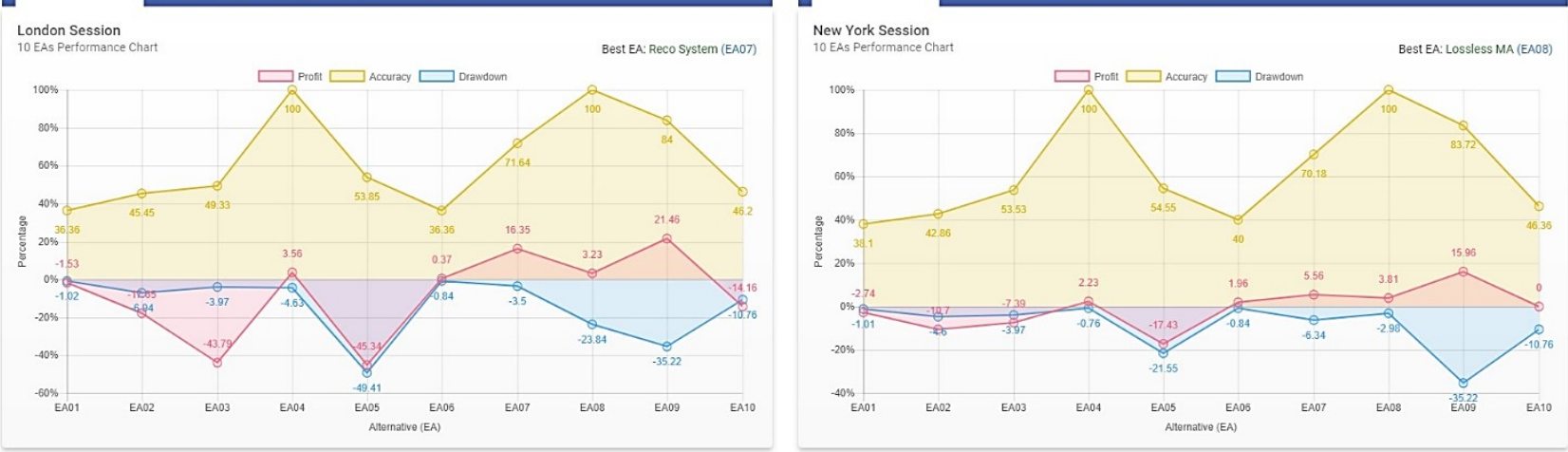

Fig. 3. Ten EAs performances by market classification 

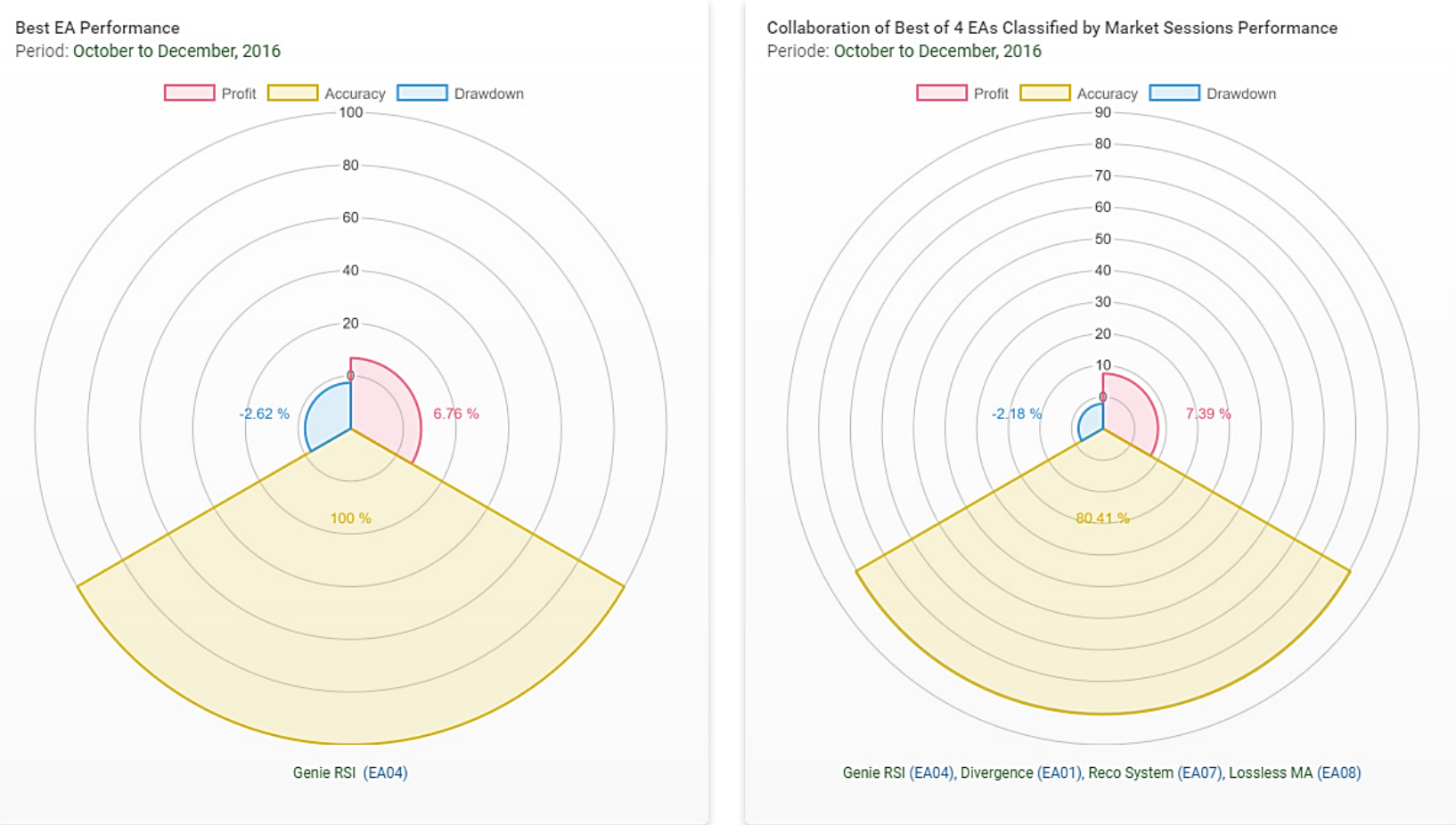

Fig. 4. EAs performance comparation
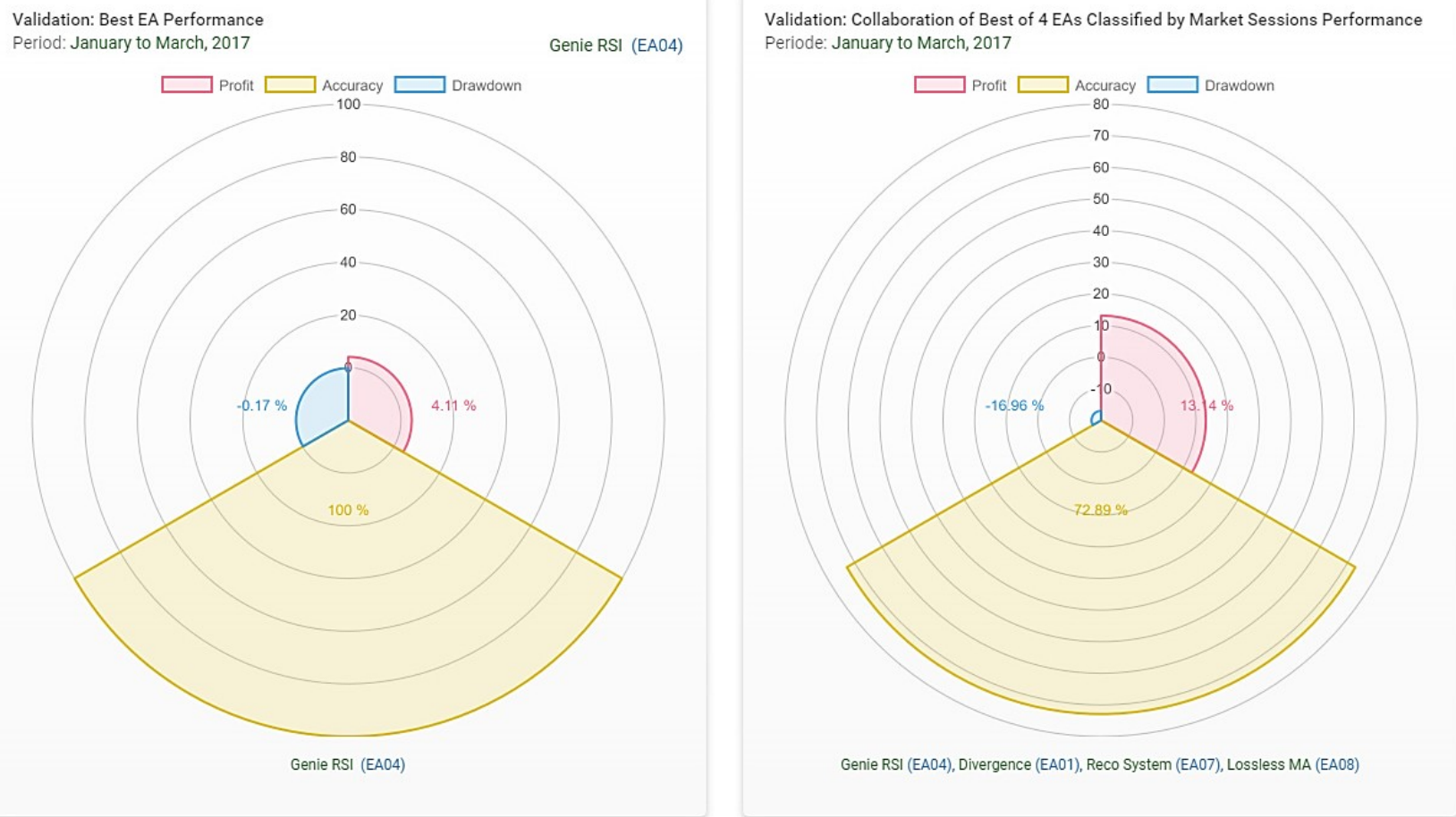

Fig. 5. EAs performance validation

\section{Conclusion}

The decision-making system with web-based ELECTRE method to determine the best collaboration EAs to be used based on its best market session performance, EAs performance are calculated by its profit, accuracy and drawdown criteria and the use of combination four EAs were best on its market session can increase profit consistently while maintaining accuracy and drawdown levels, this can be proven in the testing and validation processes with the profit increase level of $0.63(9.20 \%)$ in the testing period and 9.03 $(219.71 \%)$ in the validation period, and keep securing accuracy and drawdown levels when compared to other EAs. 


\section{References}

1. T. Balabanov, I. Zankinski, N. Dobrinkova, LargeScale Scientific Computing (LSSC) 2011, Vol 7116, 198-205 (2012).

2. R.M.C. Pinto, J.C.M. Silva, 2012 12th International Conference on Intelligent Systems Design and Applications (ISDA), 34-39 (2012).

3. P. Czekalski, M. Niezabitowski, R. Styblinski, 2015 20th International Conference on Control Systems and Science, 322-328 (2015).

4. J. Korczak, M. Hernes, M. Bac, 2015 Federated Conference on Computer Science and Information Systems (FedCSIS), 1367-1376 (2015).

5. K.K. Lai, L. Yu , S. Wang, Data Mining and Knowledge Management, Vol 3327, 243-253 (2004).

6. D. Simić, J. Gajić, V. Ilin, V. Svirčević, S. Simić, $A$ Hybrid Artificial Intelligent Systems, Vol 9648, 283295 (2016).
7. R.P. Barbosa, O. Belo, Advances in Data Mining, Medical Applications, E-Commerce, Marketing, and Theoretical Aspects, Vol 5077, 389-403 (2008).

8. R.F.B. de Brito, A.L.I. Oliveira, 2014 International Joint Conference on Neural Networks (IJCNN), 4251-4258 (2014).

9. M.H. Eng, Y. Li, Q.G. Wang, T.H. Lee, 2008 International Conference on Information Management, Innovation Management and Industrial Engineering, Vol 1, 279-282 (2008).

10. Y.L. Yong, Y. Lee, D. Nga, 2015 IEEE International Symposium on Robotics and Intelligent Sensors (IRIS), 313-317 (2015).

11. V.H.T. Kiet, R. 2005 IEEE International Conference on e-Technology, e-Commerce and e-Service, 518521 (2005).

12.Z. Liu, D. Xiao, 2009 Sixth International Conference on Fuzzy Systems and Knowledge Discovery, Vol 3, 239-243 (2009). 